\title{
LEISHMANIOSE VISCERAL CANINA - RELATO DE CASO
}

\author{
Suélen Dalegrave1; João Pedro Grassi de Araujo²; Maurício Orlando Wilnsen³ \\ ${ }^{1}$ Residência em Clínica e Cirurgia de Pequenos Animais, Pontifícia Universidade Católica do Paraná \\ (PUCPR) Toledo, PR. \\ ${ }^{2}$ Residência em Clínica, Cirurgia e Reprodução de Animais de Produção, Pontifícia Universidade \\ Católica do Paraná (PUCPR) Toledo, PR. \\ ${ }^{3}$ Doutor, Professor do eixo de Medicina Veterinária Preventiva do Curso de Medicina Veterinária, \\ Pontifícia Universidade Católica do Paraná (PUCPR) Toledo, PR.
}

DOI: $10.47094 /$ ICONRES.2021/7

\section{RESUMO}

A Leishmaniose visceral canina é uma zoonose endêmica no Brasil e possui grande importância no que diz respeito à saúde pública. É causada pelo protozoário do gênero Leishmania spp. cujo período de incubação pode variar de três meses a vários anos, mesmo quando as manifestações clínicas variam conforme a resposta imunológica do hospedeiro. O diagnóstico clínico é realizado combinando testes patológicos, sorológicos e moleculares. Foi atendido um cão, 3 anos, raça buldogue francês com histórico recorrente de dificuldade respiratória, onicogrifose, alopecia, hiperqueratose, dermatite descamativa em diversos locais do corpo lesões em região membros pélvicos, torácicos e plano labial. O exame ELISA confirmou o diagnóstico de Leishmaniose Visceral Canina. Diante da gravidade das lesões e estado clinico, foi optado pela eutanásia do animal.

PALAVRAS-CHAVES: Diagnóstico; Doença infecciosa; Protozoário.

ÁREA TEMÁTICA: Medicina veterinária

\section{INTRODUÇÃO}

A leishmaniose é uma doença infeciosa transmitida por um protozoário do gênero Leishmania spp. No Brasil, os flebotomíneos causadores dessa enfermidade pertencem basicamente a duas espécies Lutzomyia longipalpis e Lutzomyia cruzi. Esses vetores são conhecidos popularmente como mosquito palha e se reproduzem em matéria orgânica em decomposição (LIMA \& GRISOTTIB, 2018). A doença é uma das principais zoonoses do país (SILVA et al., 2017). O diagnóstico ocorre pela realização de teste rápido, sorologia, imunohistoquimica, identificação do parasita em exame 
histopatológico, métodos de Reação em cadeia da polimerase (PCR) e observação direta da forma amastigota do protozoário pela análise de esfregaço uma vez que, o paciente apresenta sinais inespecíficos ou até mesmo assintomáticos (ROCHA et al., 2020). O tratamento pode ser considerado, contudo, irá depender do quadro clínico que o paciente se apresenta (BRASIL, 2012) O presente trabalho tem como objetivo, relatar um caso de leishmaniose visceral em um cão.

\section{METODOLOGIA}

Foi atendido na clínica veterinária da Pontifícia Universidade Católica do Paraná, campus Toledo-PR, um cão, macho, da raça Bulldog Francês, com três anos de idade, pesando 8,2 kg. A queixa principal do tutor se baseava nas lesões crostosas em pele há mais de 11 meses. As lesões apresentavam ainda, eritema e hiperqueratose, localizadas principalmente em região de face e membros. A pele apresentava aspecto descamativo principalmente em região axilar e de virilha, além de membros anteriores e posteriores, além de alopecia em região que circundava as lesões. O tutor relatou também dificuldade respiratória com produção de secreção purulenta pelas narinas.

O animal já havia sido consultado por profissionais, onde o diagnóstico suposto era de dermatofitose, com infecção bacteriana secundária e hemoparasitose. O cão foi submetido a dois meses atrás, a diferentes tipos de tratamentos medicamentosos a base de antibioticoterapia, antianêmicos, corticóide e imunossupressor, sem resultado satisfatório. O paciente estava com o protocolo de vacinas éticas e vermifugação em dia. A tutor relatou que o animal se alimentava com ração seca e comida caseira. $\mathrm{O}$ animal não tinha acesso à rua ou contactantes e tomava banho em casa. A cão apresentava normorexia, normodipsia, normoquesia e normúria.

No exame clínico geral, o animal estava alerta e apresentava dificuldade respiratória, ativo, mucosas normocoradas, desidratação de 5-6\%, TPC de 2 segundos, linfonodos submandibulares, préescapulares e poplíteo estavam reativos, frequência cardíaca de $92 \mathrm{bpm}$, frequência respiratória de 30 mpm e temperatura retal de $38,7^{\circ} \mathrm{C}$. Não foram identificadas alterações na palpação abdominal. Foi observado que o animal apresentava onicogrifose (Figura 1B), alopecia, hiperqueratose, dermatite descamativa em diversos locais do corpo, lesões crostosas e ulcerativas em região membros pélvicos, torácicos e plano labial (Figura 1A, C e D). Suspeitando-se de leishmaniose visceral canina e hemoparasitose. 
Figura 1: Cão, macho, da raça buldogue francês, três anos de idade. A- Lesões ulcerativas e crostosas em face; B- Onicogrifose com unhas já aparadas pela tutora e lesão crostosas ulcerativa em membro esquerdo; C e D- Alopecia e lesões descamativas generalizadas

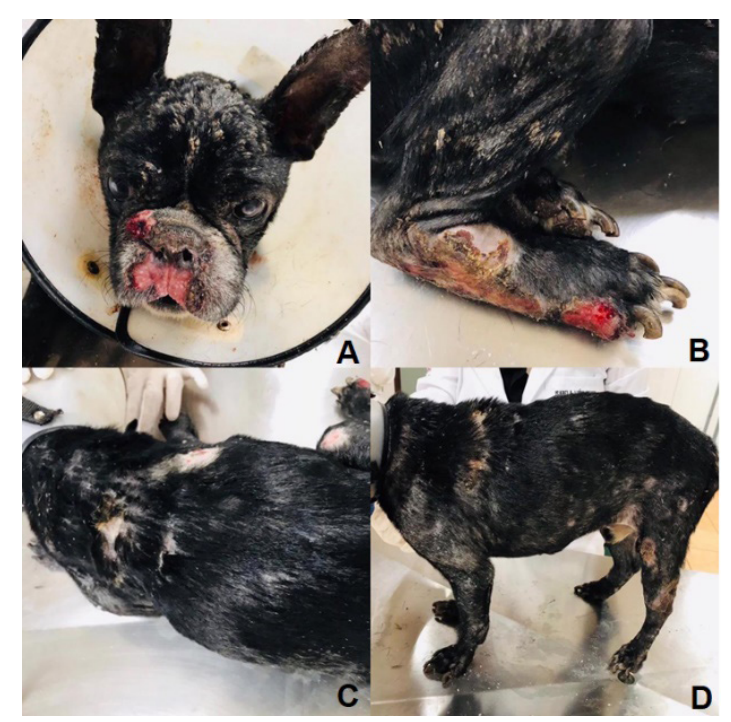

Fonte: Arquivo pessoal Suélen Dalegrave.

O resultado do hemograma, apontou anemia normocítica normocrômica, leucopenia com desvio à esquerda e trombocitopenia. Nos exames bioquímicos hipoalbuminemia e hiperproteinemia. Foram solicitados raspados de pele para pesquisa de ácaros, cultura fúngica, RIFI para Erhlichia canis e Babesia spp os quais evidenciaram resultados negativos. O exame imunocromatográfico, ELISA confirmou o diagnóstico de Leishmaniose Visceral Canina. Foi sugerido exame sorológico para leishmaniose, porém, tutora não aceitou. Após foi indicado, o tratamento com antimoniato de meglumina na dose de $2 \mathrm{mg} / \mathrm{kg} / \mathrm{dia}$, durante 45 dias, alopurinol $10 \mathrm{mg} / \mathrm{kg} / \mathrm{BID}$ durante 90 dias e coleira repelente. Diante da gravidade do quadro, a tutora optou pela eutanásia realizada com propofol e cloreto de potássio $19,1 \%$ dose ao efeito.

\section{RESULTADOS E DISCUSSÕES}

Os cães acometidos por leishmaniose muitas vezes podem ser assintomáticos. Alguns achados permitiram identificar alterações sistêmicas como hepatomegalia, esplenomegalia, epistaxe, secreção nasal e ocular, febre, emagrecimento progressivo, poliúria e polidipsia, diarreia, onicogrifose e lesões dermatológicas (FREIRE \& MORAES, 2019). O paciente em questão apresentou dificuldade respiratória, onicogrifose, alopecia, hiperqueratose, dermatite descamativa em diversos locais do corpo, lesões crostosas e ulcerativas em região membros pélvicos, torácicos e plano labial.

O perfil hematológico de anemia normocítica normocrômica, leucopenia ou leucocitose e trombocitopenia, são achados frequentes em pacientes com a doença, causados pela consequência 
do sequestro de hemácias do baço, eritropoiese diminuída devido a supressão da medula óssea, deficiência nutricional ou hemorragias (FONSECA JÚNIOR, et al. 2021). No avaliações bioquímicas a hiperproteinemia com hipoalbuminemia, observados no caso, podem ser normalmente encontrados pela fração reduzida de albumina/globulina, outras enzimas que podem estar aumentadas são aminotransferase (ALT), Fosfatase alcalina (FA) e Gama-glutamiltransferase (GGT) (GODOY et al., 2017).

O diagnóstico do animal foi realizado pelo método de imunocromatográfico ELISA. Contudo, pode ser realizado também pelos sinais clínicos quando presentes, teste rápido, sorologia, imunohistoquimica, identificação do parasita em exame histopatológico, métodos de Reação em cadeia da polimerase (PCR) e a análise do esfregaço pela observação direta da forma amastigota do protozoário (ROCHA et al., 2020).

O tratamento proposto para o caso em questão foi de antimoniato de meglumina na dose de $2 \mathrm{mg} / \mathrm{kg} /$ dia durante 45 dias que foi aceito em nota Técnica $\mathrm{n}^{\circ}$ 11/2016, assinada pelo Ministério da Agricultura Pecuária e Abastecimento (MAPA) vem sendo empregada (BRASIL, 2016), juntamente com outros medicamentos coadjuvantes como o alopurinol $10 \mathrm{mg} / \mathrm{kg} / \mathrm{BID}$ durante 90 dias (FONSECA JÚNIOR, et al. 2021). Os animais que não podem receber tratamento devem ser submetidos à eutanásia com base na Resolução n ${ }^{\circ} 1000$ do CFMV, utilizando anestesia e medicamentos adequados (BRASIL, 2012). A prevenção e profilaxia de ambientes ainda é considerada a melhor opção para controlar a zoonose. Atualmente, existem coleiras e inseticidas tópicos na forma de spray a base de permetrina usadas como repelentes, além da utilização de protocolos vacinais que auxiliam a prevenção da doença (MATIAS et al., 2020).

\section{CONCLUSÃO}

A leishmaniose visceral canina possui grande importância no âmbito da saúde pública e animal, por se tratar de uma zoonose. O conhecimento do agente etiológico, sinais clínicos, exames, afim de garantir eficácia no diagnóstico e consequentemente determinar uma conduta adequada para cada caso, sendo a melhor forma de se combater a doença é através de ações que propõem o controle do vetor.

\section{REFERÊNCIAS}

BRASIL. Conselho Federal de Medicina Veterinária. Resolução n 1000, de 11 de maio de 2012. Dispõe sobre procedimentos e métodos de eutanásia em animais e dá outras providências. Brasília: Diário Oficial da União de 17 de maio de 2012.

BRASIL. Ministério da Agricultura Pecuária e Abastecimento. Nota Técnica No 11/2016/CPV/DFIP/ SDA/GM/MAPA, 2016. 
FREIRE, C.G.V. \& MORAES, M.E. Cinomose canina: aspectos relacionados ao diagnóstico, tratamento e vacinação. Pubvet. v.13, n.2, a263, p.1-8, 2019.

FONSECA JÚNIOR, José Duarte da; MAZZINGHY, Cristiane Lopes; FRANÇA, Erycka Carolina; PINOW, Ana Clara Silva \& ALMEIDA, Katyane de Sousa. Leishmaniose visceral canina: revisão. Pubvet, v. 15, n. 3, p. 1-8, 2021.

GODOY, K.C.S., ANTUNES, T.R., BRAZ, P.H., ASSIS, A.R, OLIVEIRA, G.G., SILVEIRA, A.W., SILVA, M. P. \& SOUZA, A. I. Comportamento dos marcadores bioquímicos de injúria hepática nos cães com leishmaniose visceral. Pubvet, v. 11, n. 7, p. 670-675, 2017.

LIMA, C.C. \& GRISOTTIB, M. Relação humano-animal e leishmaniose: repercussões no cotidiano de indivíduos inseridos em região endêmica. Saúde Sociedade, v. 27, n. 4, p. 1261-1269, 2018.

MATIAS, Erica Pereira; SANTOS, Fernanda Fonseca; GUIMARÃES, Juliana Plácido \& CHUCRI, Thaís Martins. EFEITOS ADVERSOS DA VACINA LEISH-TEC® EM CÃES SORONEGATIVOS PARA LEISHMANIOSE VISCERAL. Brazilian Journal Of Development, [S.L.], v. 6, n. 7, p. 53019-53028, 2020.

ROCHA, S.T.F., SHIOSI, R.K. \& FREITAS, A.B.M. Leishmaniose visceral canina - Revisão de literatura. Revista científica de medicina veterinária, n.34, 2020. 